\title{
Turismo Étnico em comunidades quilombolas: perspectiva para o etnodesenvolvimento em Filipa (Maranhão, Brasil)
}

\author{
Ethnic Tourism in quilombolas communities: \\ perspective for the ethnodevelopment in Filipa (Maranhão, Brazil)
}

\author{
Rosijane Evangelista da Silva (SILVA, R. E.)* e \\ Karoliny Diniz Carvalho (CARVALHO, K. D.) ${ }^{* *}$
}

\begin{abstract}
RESUMO - O artigo reflete sobre a prática turística nos territórios remanescentes quilombolas, buscando analisar o processo de inserção da comunidade de Filipa, Maranhão (Brasil), no turismo étnico. O estudo relaciona questões referentes à memória (POLLACK, 1989), identidade (CASTELLS, 1999; HALL, 2001; CANCLINI, 2000) e patrimônio cultural (CASTILLO-RUIZ, 1996 apud ZANIRATO e RIBEIRO, 2006), enfatizando-o como recurso (YÚDICE, 2004) para o turismo cultural (COSTA, 2009), notadamente para o segmento turismo étnico. Partindo-se de uma pesquisa bibliográfica e documental (DENCKER, 1998) conclui-se que o patrimônio cultural da comunidade de Filipa pode contribuir para o etnodesenvolvimento do local, por meio de um aproveitamento turístico balizado nos princípios da sustentabilidade cultural.
\end{abstract}

Palavras-chave: Turismo Étnico; Sustentabilidade; Filipa-Maranhão.

ABSTRACT - The article reflects on the tourist practice in the quilombolas remaining territories, trying to analyze the insert process of Filipa community, Maranhão (Brazil), in the ethnic tourism. This study is related to memory (POLLACK, 1989), identity (CASTELLS, 1999; HALL, 2001; CANCLINI, 2000) and cultural heritage (CASTILLO-RUIZ, 1996 apud ZANIRATO e RIBEIRO, 2006), emphasizing it as a resource (YÚDICE, 2004) for the cultural tourism (COSTA, 2009), especially for the ethnic tourism segment. Starting from a literature and a documentary review (DENCKER, 1998), it can be concluded that the Filipa community cultural heritage can contribute to the local ethnodevelopment, throughout a tourist utilization marked out in the principles of cultural sustainability.

Key words: Ethnic Tourism; Sustainability; Filipa-Maranhão.

\footnotetext{
* Bacharel em Turismo pela Universidade Federal do Maranhão (UFMA). Mestranda em Cultura e Turismo pela Universidade Estadual de Santa Cruz (UESC), Ilhéus, Bahia (BA). Endereço para correspondência: Rua Boa Esperança, 99, apartamento 405, Bloco IV, condomínio Fernando de Noronha, Angelim. CEP: 65490-250 - São Luís - Maranhão (MA/Brasil). E-mail: fedele.e@hotmail.com.

** Bacharel em Turismo pela Universidade Federal do Maranhão (UFMA). Mestranda em Cultura e Turismo pela Universidade Estadual de Santa Cruz (UESC), Ilhéus, Bahia (BA). Bolsista da Fundação de Amparo à Pesquisa do Estado da Bahia (FAPESB). Endereço para correspondência: Rua Barão do Rio Branco, Quadra I, número 14, (Sítio Leal). CEP: 65045-340 - São Luís - Maranhão (MA/Brasil). Email: karol27_turismo@yahoo.com.br
}

Turismo \& Sociedade, Curitiba, v. 3, n. 2, p. 203-219, outubro de 2010 


\section{INTRODUÇÃO}

Na contemporaneidade, o turismo caracteriza-se como um importante instrumento de dinamização sócio-econômica, apresentando um viés predominantemente cultural. Conhecer lugares, manter contato com a dimensão material e simbólica das comunidades, e vivenciar as experiências de um lugar é compartilhar de seus elementos e significados singulares, participando da representatividade cultural dos locais visitados.

A riqueza cultural de uma comunidade ao ser preservada como forma de manutenção do grupo é utilizada como fomento ou elemento potencializador para a atividade turística, principalmente neste momento em que se observa o crescente interesse pela pluralidade étnica e pela diversidade cultural.

O presente artigo objetiva refletir sobre o turismo cultural nos territórios remanescentes quilombolas, buscando analisar as possibilidades de aproveitamento turístico do legado étnico da comunidade de Filipa, localizada no Estado do Maranhão, enquanto fator de desenvolvimento sócioeconômico.

Como aporte teórico para a fundamentação do trabalho, o estudo relaciona questões referentes à memória (POLLACK, 1989), identidade (CASTELLS, 1999; HALL, 2001; CANCLINI, 2000) e patrimônio cultural (CASTILLO-RUIZ, 1996 apud ZANIRATO e RIBEIRO, 2006), enfatizando-o como recurso (YÚDICE, 2004) para o turismo cultural (COSTA, 2009), notadamente para o segmento turismo étnico.

Partindo-se de uma pesquisa de caráter bibliográfico, complementada por análise documental (DENCKER, 1998), buscou-se também a pesquisa de campo, mediante a observação sistemática da realidade investigada, por meio de visitas periódicas à comunidade quilombola de Filipa. A coleta de dados ocorreu nos meses de fevereiro e março de 2009.

Utilizando como instrumento metodológico a observação não participante, tornou-se possível obter informações sobre o legado étnico da comunidade, as articulações dos agentes em torno da proposta de implantação do turismo naquela região, além de identificar as oportunidades para o etnodesenvolvimento local.

Diante do exposto, a argumentação proposta encontra-se dividida em seções. Inicialmente, apresenta-se uma breve discussão sobre patrimônio cultural, identidade e 
memória, relacionando-os aos territórios quilombolas. Em seguida, expõe-se o processo de articulação entre legados étnicos e o turismo cultural, destacando-o como vetor para o fortalecimento das identidades culturais e para a promoção do etnodesenvolvimento em comunidades tradicionais.

Posteriormente, o estudo apresenta uma discussão sobre a construção do olhar turístico no território quilombola de Filipa, Maranhão, ressaltando as suas particularidades, bem como as estratégias de conformação adotadas para a sua configuração como produto turístico baseado no legado étnico.

Parte-se do pressuposto de que a atividade turística pode contribuir para o etndodesenvolvimento local e para o enriquecimento da relação entre turistas e residentes por meio de um aproveitamento balizado nos princípios da sustentabilidade cultural.

\section{TERRITÓRIOS ÉTNICOS: ENTRE MEMÓRIAS E TRADIÇÕES}

O patrimônio cultural apreendido como testemunho das diversas vivências dos grupos sociais apresenta-se sob vários matizes, considerando os aspectos tangíveis e espirituais que produzem sentido e significado ao legado cultural transmitido de geração a geração. Nele estão inseridos todos os saberes e fazeres populares, as festas e celebrações, a gastronomia, o artesanato, o patrimônio histórico-arquitetônico, a religiosidade, ou seja, toda produção material e simbólica dos grupos sociais enquanto partícipes de um integrado e complexo sistema de representação simbólica.

Por meio dele, os indivíduos estabelecem trocas culturais, manifestando seus vínculos identitários. Para Castells (1999, p. 23), a identidade é um processo social, sendo definida como "fontes de significados e experiências construídas [...] a partir da matéria-prima fornecida pela história, geografia, biologia, instituições de poder e revelações de cunho religioso”. Tais significações são constantemente remodeladas e construídas, isto é, obedecem a processos de seleção e apropriação por parte dos grupos sociais, de acordo com determinado momento ou contexto histórico. Conforme assinala Sodré (1999, p. 45): 
A identidade afirma-se primeiro como um processo de diferenciação interna e externa, isto é, de identificação do que é igual e do que é diferente, e em seguida como um processo de integração ou organização das forças diferenciais, que distribui os diversos valores e privilegia um tipo de acento.

Assim, os indivíduos estabelecem determinados elementos que são apreendidos como traços distintivos de sua cultura, e se tornam alicerces para a construção das identidades. Na contemporaneidade, as identidades tornam-se cada vez mais compartilhadas, sofrendo constantes processos de hibridismo cultural, o que resulta para Canclini (2000) na formação de indivíduos traduzidos, que assumem diferentes posições ou referências identitárias.

Nesse contexto, o patrimônio cultural em sentido amplo passa a ser entendido, conforme expõem Castillo-Ruiz, 1996 apud Zanirato e Ribeiro, 2006 ${ }^{1}$ como o "conjunto de elementos naturais ou culturais, materiais ou imateriais, herdados do passado ou criados no presente, no qual um determinado grupo de indivíduos reconhece sinais de sua identidade".

De acordo com Pollack (1989) através da memória intensifica-se o sentido de pertencimento dos grupos sociais a um passado ou origem comum delimitando, nesse sentido, fronteiras sócio-culturais. Na visão de Murta e Albano (2002, p. 125), “a memória é, portanto, um elemento constitutivo da identidade, tanto coletiva quanto individual, e elemento importante para o reconhecimento e a valorização de indivíduos ou grupos, agindo para reforçar sua auto-estima”.

Assim, o patrimônio cultural implica sentidos de permanência, pertencimento e persistência, considerando-se que a produção material e simbólica de uma determinada comunidade torna-se elo de identificação do grupo a um ethos cultural comum, vetor de transmissão e compartilhamento de memórias individuais e coletivas, e das tradições. Essas são reinterpretadas e reconfiguradas no presente, porém, mantendo-se o substrato que lhe deu origem.

Essa configuração pode ser analisada em comunidades ditas tradicionais, nas quais a identidade é percebida e reelaborada, segundo Poutignat e Streiff-Fenart (1998)

${ }^{1}$ CASTILLO-RUIZ. Hacia una nueva definición de patrimonio histórico? PH Boletín del Instituto Andaluz del Patrimonio Histórico, Sevilla: IAPH, n. XVI, set. 1996, p. 22. 
por meio da diferença, possuindo um sentido marcadamente territorial. Conforme observa Haesbaert (1999, p. 178-179):

\begin{abstract}
A identidade social é também uma identidade territorial quando o referente central para a construção desta identidade parte ou transpassa o território. Território que pode ser percebido em suas múltiplas perspectivas, desde aquela que de uma paisagem como espaço cotidiano, vivido, que simboliza uma comunidade - até um recorte geográfico mais amplo, ou em tese mais abstrato como o Estado nação
\end{abstract}

De acordo com Diegues e Arruda (2001), a expressão comunidade tradicional é quase sempre utilizada para identificar povos e grupos sociais que guardam uma continuidade histórica, cultural e identitária desde a conquista européia da América. No Brasil tal expressão está associada às comunidades que desenvolveram modos de produção em que o trabalho não é visto como mera mercadoria e a dependência ao mercado existe, mas não é total.

Essas comunidades desenvolvem formas particulares de manejo dos recursos naturais que não visam diretamente ao lucro, mas à reprodução cultural e social, bem como percepções e representações em relação ao mundo natural e cultural marcadas pela idéia harmônica de associação com a natureza e seus ciclos. Entre as chamadas populações tradicionais destacam-se as comunidades rurais remanescentes de quilombos.

O decreto governamental número 6.040 de 07/02/2007 que institui a Política Nacional de Sustentabilidade dos Povos e Comunidades tradicionais - PNPCT (BRASIL, 2007) conceitua comunidades tradicionais como grupos culturalmente diferenciados e que se reconhecem como tais, que ocupam e usam territórios e recursos naturais como condição para sua reprodução social, religiosa, ancestral e econômica, utilizando conhecimentos, inovações e práticas geradas e transmitidas pela tradição.

Redutos históricos da resistência negra, as comunidades quilombolas enquadram-se nesse perfil. Segundo Silva (2004), um dos conceitos mais amplamente disseminados em nível nacional é o da Associação Brasileira de Antropologia - ABA, que define tais comunidades como "toda comunidade negra rural que agrupe 
descendentes de escravos vivendo da cultura de subsistência e onde as manifestações culturais têm forte vínculo com o passado (ABA apud SILVA, 2004, p. 16) 2””.

Tal conceito designa a situação da etnia negra em diferentes regiões e contextos, sendo utilizado para caracterizar um legado cultural e material que oferece a esses grupos uma referência presencial no sentido de ser e pertencer a um lugar e a um grupo específico.

Assim, os territórios quilombolas resultam de um tipo particular de percepção e apropriação do espaço geográfico, sendo constituídos por formas de organização social, comunicação grupal e laços de solidariedade comunitária específicos, ligando os indivíduos a um passado ou origem étnica comum. Apresentam-se como verdadeiros sítios simbólicos de pertencimento, reveladores de vivências, crenças, ritos, rituais, celebrações, costumes e estilos de vida dessas comunidades. Na visão de Zaoual (2006, p. 37), “os sítios apresentam, com efeito, esta extensão imbricada que os tornam, apesar de seu caráter único, entidades plurais que vivem da diversidade circundante”.

A identidade étnica de um grupo é o alicerce para sua forma de organização, para sua relação com os demais grupos e de seu agir político. A atitude pela qual os grupos sociais definem o próprio pertencimento é resultado de uma confluência de fatores determinados por eles mesmos, no qual constam itens como uma ancestralidade comum, formas de organização política e social, elementos lingüísticos e religiosos. Para Poutgnat e Streiff-Fenart (1998, p. 129):

\begin{abstract}
A etnicidade não é vazia de conteúdo cultural (os grupos encontram 'cabides' nos quais pendurá-la), mas ela nunca é também a simples expressão de uma cultura já pronta. Ela implica sempre um processo de seleção de traços culturais dos quais os atores se apoderam para transformá-los em critérios de consignação ou de identificação com um grupo étnico.
\end{abstract}

As comunidades quilombolas são comunidades e grupos sociais cujos processos identitários de construção sócio-cultural os distinguem do restante da sociedade. Tais processos tornam-se dinâmicos, balizados em mecanismos sucessivos de construção e reconstrução identitárias, nas quais os atores sociais se apropriam, selecionam e reelaboram determinados atributos culturais, de acordo com os diferentes contextos ou momentos históricos.

\footnotetext{
${ }^{2}$ ABA. Associação Brasileira de Antropologia. Disponível em: <http://www.abant.org.br/>.
} Turismo \& Sociedade, Curitiba, v. 3, n. 2, p. 203-219, outubro de 2010 
Baseando-se nessa proposição observa-se que as comunidades tradicionais, além de se constituírem em lugares mantenedores de uma memória étnica e cultural específica, vêm sendo incorporadas sob a forma de roteiros e atrações culturais, às demandas das sociedades contemporâneas, nas quais se inserem o lazer e o turismo.

\section{TURISMO CULTURAL E ETNODESENVOLVIMENTO: INTERFACES}

O turismo entendido como um dos principais fatores do trânsito ou da mobilidade humana configura-se como uma atividade marcadamente cultural, impulsionado pelo desejo dos grupos sociais em vivenciar experiências diferenciadoras de seu cotidiano. Dessa forma, a atividade projeta o patrimônio cultural como instrumento mediador de aprendizagem e educação. Na visão de Moesch (2001, p. 9) o turismo constitui-se em:

\footnotetext{
Uma combinação complexa de inter-relacionamentos entre produção e serviços, em cuja composição integra-se uma prática social com base cultural, com herança histórica, a um meio diverso, cartografia natural, relações sociais de hospitalidade, troca de informações interculturais.
}

Diante do panorama crescente de profundas transformações nas relações sociais, do processo de mundialização do capital econômico e cultural, atrelada à disseminação de redes globais em amplos setores da realidade econômica, o turismo proporciona a redefinição dos usos dos territórios, agenciando as especificidades naturais e culturais das regiões, e gerando oportunidades de desenvolvimento social e econômico. Assim, os territórios de identidade transformam-se em territórios turísticos, com repercussões na vida social, econômica e cultural das comunidades receptoras.

Nesse contexto, os turistas tidos como culturais possuem como principal motivação o desejo de entrar em contato com diferentes culturas, visitando os elementos representativos do patrimônio de uma determinada comunidade: conjuntos arquitetônicos, sítios arqueológicos, danças típicas, religiosidade, gastronomia, o artesanato, a musicalidade, performances artística. Assim, o patrimônio cultural apresenta-se como atrativo significativo para os turistas, especialmente para aqueles que buscam na apreciação do outro, um diferencial em relação às suas vivências habituais. 
O conhecimento sobre a dimensão material e simbólica reelaborada na cotidianidade de povos e comunidades específicos através de suas diversas formas de representação constitui-se em um viés integrador, gerando oportunidades efetivas de educação e aprendizado intercultural. Na visão de Costa (2009, p. 190):

O turismo cultural pode ser compreendido como um segmento da atividade turística que, por meio da apreciação, da vivência e da experimentação direta dos bens do patrimônio cultural, material e imaterial, e da mediação da comunicação interpretativa, proporciona aos visitantes a participação em um processo ativo de construção de conhecimentos sobre o patrimônio cultural e sobre seu contexto sócio-histórico. Em última escala, este processo auxiliará na produção de novos conhecimentos e a conservação dos bens visitados.

Segundo Urry (1996), enquanto atividade econômica o turismo materializa-se nas relações comerciais que se estabelecem nos destinos com a presença dos visitantes, variando de acordo com o caráter motivacional dos grupos sociais e com as diferentes formas de apresentação das culturas visitadas durante a performance ou experiência turística. No segmento do turismo cultural surgem, assim, várias especialidades, dentre as quais se destacam o turismo gastronômico, o religioso, e o turismo étnico.

O turismo étnico ou o turismo baseado no legado étnico vem se afirmando como uma alternativa frente ao turismo massificado no qual predomina o consumo desenfreado das culturas locais. Sob o paradigma da diversidade cultural e da plurietnicidade, os turistas culturais apresentam-se como grupos de consumidores interessados na vivência cultural no âmbito de comunidades remanescentes de etnias específicas, ou naquelas em que predomina a representação do legado cultural herdado ao longo de processos históricos e sociais e reinterpretado no presente sob novas significações.

De acordo com a Organização Mundial de Turismo - OMT (2003, p. 168), o turismo étnico “é voltado para as tradições e estilo de vida de um grupo e utilizado, principalmente, para destacar o turismo nas comunidades ou enclaves específicos, em processo de desenvolvimento". Considera-se que a vivência dos turistas com os elementos do patrimônio cultural pode contribuir para o fortalecimento das identidades e para a revalorização da memória e da cultura locais.

Segundo o Ministério do Turismo (BRASIL, 2006, p. 13), “o turismo étnico é a vivência de experiências autênticas e o contato direto com os modos de vida e a identidade dos grupos étnicos”. Consiste, portanto, na busca pela interação e integração Turismo \& Sociedade, Curitiba, v. 3, n. 2, p. 203-219, outubro de 2010 
dos turistas com o cotidiano de comunidades que apresentam determinadas características sociais, econômicas, além de tradições culturais baseadas num forte sentido de territorialidade. O objetivo maior relaciona-se à busca pelo conhecimento e aprendizado intercultural.

O segmento do turismo étnico baseia-se nas novas necessidades de consumo de experiências identificadas e percebidas como autênticas tanto por parte da demanda turística, quanto por parte das comunidades receptoras. Para Beni (2002, p. 145) no turismo étnico os grupos se deslocam na busca:

[...] de suas origens étnicas locais e regionais, e também no legado históricocultural de sua ascendência comum. Incluem-se aí ainda aqueles que se deslocam com objetivos eminentemente antropológicos para conhecer "in loco" as características étnico-culturais daqueles povos que constituem o interesse de sua observação (Grifo do autor).

Nesse sentido, ao revigorar o patrimônio cultural relacionando-o ao presente, o turismo cultural oportuniza à comunidade um importante aprendizado sobre a sua própria trajetória cultural, destacando as características históricas e culturais dos territórios étnicos, ressaltando assim, a importância dos referenciais culturais para o revigoramento ou fortalecimento das identidades.

Conforme analisa Yúdice (2004), o patrimônio cultural, nesses casos, é entendido como recurso, sendo utilizado como estratégia para o desenvolvimento sócioeconômico de muitas comunidades. Assim, muitas localidades têm enfatizado a preservação dos diferentes legados étnico-culturais, objetos e artefatos de significância cultural, bens simbólicos e manifestações populares, inserindo-os no mercado de consumo cultural. Para Graburn (2009, p. 26):

O turismo étnico depende de transmitir - mediante folhetos, vídeos e descrições em outros lugares, artes turísticas, representações e encenações no local - a fascinante diferença, e até o exotismo, da comunidade receptora. As mesmas forças também dão forma às autorepresentações regionais e até nacionais naquelas partes do mundo que são consideradas “étnicas”. Em todo lugar, a “cultura autêntica” é colocada na vitrine (Grifo do autor).

Em articulação aos processos de produção e consumo de mercadorias e bens simbólicos que operam em nível global, na qual a atividade turística se insere, reacendem-se as discussões sobre o desenvolvimento sócio-cultural dos territórios numa 
perspectiva local. Na visão de Santana (2009) os debates em torno dessa questão, de um modo geral, referem-se aos resultados - nem sempre benéficos às comunidades receptoras - da encenação das culturas, valores e tradições enquanto produtos destinados ao consumo visual e estético, na perspectiva de atender às necessidades culturais dos visitantes. A esse respeito Bahl (2004, p. 66) comenta que "o artificialismo nem sempre é o desejado, mas torna-se um recurso para a manutenção do sonho daqueles turistas sequiosos em conhecer aspectos da cultura de um local e de seu comportamento”. Ao mesmo tempo enfatiza que:

[...] a participação popular pelo incentivo às manifestações locais torna-se um ponto benéfico em que a localidade se prepara a partir de seus próprios interesses, e que justamente serão a sua marca registrada e diferencial, evitando-se o artificialismo e a promoção de fenômenos produzidos e sem razão de existirem (BAHL, 2004, p. 66).

A noção de etnodesenvolvimento é quase sempre confundida com o conceito de desenvolvimento sustentável das comunidades étnicas, porém tal noção é pouco abrangente e, apesar deste conceito englobar a dimensão da sustentabilidade, seu papel enquanto fator revigorante do patrimônio cultural e fortalecedor do pertencimento étnico envolve questões mais amplas.

De acordo com Diegues e Arruda (2001), o discurso sobre esse tema surgiu no contexto latino-americano de forma mais consistente a partir da década de oitenta como fruto de debates da reunião de especialistas em etnodesenvolvimento e etnocídio em São José da Costa Rica. Seu conceito se formou como alternativa às teorias desenvolvimentistas e etnocidas que de acordo com Verdum, 2002 apud Farias (2003, p. 72$)^{3}$, “tomavam as sociedades indígenas e as comunidades tradicionais em geral como obstáculo ao desenvolvimento, à modernização e ao progresso”.

Stavenhagem, 1985 apud Grünewald (2002, p. 51) ${ }^{4}$ propõe uma caracterização sobre etnodesenvolvimento como "um desenvolvimento que mantém o diferencial sociocultural de uma sociedade, ou seja, sua etnicidade”. Assim, essa denominação perpassa pelas questões da sustentabilidade, mas considera além delas. Baseando-se

3 VERDUN, R. Etnodesenvolvimento e mecanismos de fomento do desenvolvimento dos povos indígenas: a contribuição do subprograma Projetos Demonstrativos (PDA). In: LIMA, A. C.; BARROSO, M. (Orgs.). Etnodesenvolvimento e políticas públicas: bases para uma nova política indigenista. Rio de Janeiro: Contra capa/LACED, 2002.

4 STAVENHAGEM, R. Etnodesenvolvimento: uma dimensão ignorada do pensamento desenvolvimentista. In: Anuário Antropológico 84. Rio de Janeiro, p. 11-44, 1985.

Turismo \& Sociedade, Curitiba, v. 3, n. 2, p. 203-219, outubro de 2010 
nessa definição, o etnodesenvolvimento significa que "a etnia, autóctone, tribal ou outra, detém o controle sobre suas próprias terras, seus recursos, sua organização social e sua cultura e é livre para negociar com o Estado o estabelecimento de relações segundo seus interesses”.

Dessa forma, pressupõe e exercita a capacidade social dos atores de comunidades tradicionais por meio de projetos definidos de acordo com seus valores e anseios, alicerçados nos recursos reais e potenciais disponíveis no seu território, na utilização de seus significados e experiências históricas e coletivas, no sentido de guiar de forma autônoma o seu desenvolvimento.

\section{A COMUNIDADE QUILOMBOLA DE FILIPA E BUSCA PELO ETNODESENVOLVIMENTO}

A comunidade quilombola de Felipa localiza-se no município de Itapecuru, distante 120 km de São Luís, capital do Maranhão, tendo como via de acesso a BR 135. Conforme apresentado por Silva (2003), o território possui uma área de 428 hectares, abrigando 35 famílias descendentes de mesmo tronco familiar, totalizando 170 pessoas. O capital social e as sinergias culturais das comunidades tradicionais e especificamente da comunidade de Filipa são estímulos para a implantação da atividade turística tanto no espaço natural - envolvendo atividades ligadas ao meio ambiente e a rotina rural quanto do turismo cultural - direcionado para a vivência de tradições e costumes específicos da comunidade quilombola.

O potencial turístico de Filipa está baseado nos seus aspectos naturais e culturais. Como atrativo natural destaca-se o rio Itapecuru, matas inexploradas e paisagens verdes que favorecem a implantação de trilhas e práticas de contemplação, lazer e descanso. Ressaltam-se ainda as possibilidades de trocas culturais mediante o contato com as pessoas da comunidade e o conhecimento sobre as práticas rurais que ali se desenvolvem.

Ao visitante pode ser oferecido o contato direto com a vida do campo, possibilitando-lhe uma experiência genuína de mergulho na realidade rural e de contato com a natureza, por meio da organização comunitária e dos valores e práticas de 
sociabilidade que ordenam a vida cotidiana do lugar (por exemplo, as produções nos campos de cultivo e a confecção de farinha), complementadas pelas tradições orais.

Dentre os aspectos culturais destaca-se o Tambor de Crioula, parte significativa do lazer e do imaginário cultural local. Herança dos ancestrais, o Tambor de Crioula em Filipa não obedece a um calendário específico de apresentações. Configura-se como elemento do lazer comunitário que pode ser brincado e ensinado aos turistas em qualquer época, sem comprometer o aspecto tradicional da brincadeira. A própria característica afro-descendente da comunidade, o status de comunidade tradicional e o modo de produção sustentável já despertam o interesse dos visitantes.

Outra festa tradicional é o Festejo em homenagem a São Sebastião, padroeiro local. O festejo harmoniza os elementos religiosos e profanos, pois além da parte ritual representada pela novena que precede a festa, da missa e da ladainha rezada em latim realizada na capela dedicada ao Santo localizada no centro do povoado, conta também com torneios de futebol e baile regado ao som do reggae $e^{5}$. A festa acontece no segundo final de semana de outubro e atrai muitos turistas para a região. Entretanto, observa-se a necessidade de implantação de uma infraestrutura básica e de serviços visando à satisfação das necessidades dos visitantes.

Em Filipa, o legado e as singularidades culturais organizados em padrões muito particulares reforçam a participação e o protagonismo da comunidade na implantação e gestão do turismo alicerçado na perspectiva de um desenvolvimento endógeno e sustentável. A comunidade de Filipa tem experimentado desde meados dos anos noventa um processo de transformação.

O desejo de melhorias foi despertado a partir de uma revalorização dos sentidos identitários culturais e coletivos de pertencimento, e do fortalecimento de suas expressões étnicas que levou os atores locais a consolidar laços de união visando uma organização comunitária e uma articulação com instituições representativas das comunidades tradicionais em esferas mais abrangentes.

Conforme analisa Silva (2003), as iniciativas vão desde a implantação em parceria com a Empresa Brasileira de Pesquisa Agropecuária - EMBRAPA/MA de um projeto piloto de criação de galinhas caipiras híbridas, implantação de técnicas de cultivo de mandioca e de uma agroindústria de farinha comunitária visando o aumento

${ }^{5}$ Ritmo Jamaicano difundido no Estado do Maranhão em meados da década de 1970. Turismo \& Sociedade, Curitiba, v. 3, n. 2, p. 203-219, outubro de 2010 
da produtividade, até uma plantação clonal de castanha de caju para distribuir sementes para outras comunidades e produtores, além de montagem de tanques para cultivo de peixes com vistas a transformar-se em um equipamento pesque e pague.

Devido às características particulares do conjunto comunitário, o desenvolvimento dessas iniciativas de pequeno porte tem produzido bons resultados e despertado o interesse pelo modo de vida e de produção de Filipa. Nesse sentido, observa-se a chegada espontânea de pequenos grupos de visitantes interessados na busca dos produtos locais, no contato com a comunidade ou na tranqüilidade das belezas locais.

Assim, emergem formas ainda incipientes de turismo com base no legado étnico, que apesar de não gerarem recursos suficientes para satisfazer as necessidades da comunidade, começam a despertar o interesse dos comunitários. O turismo baseado no legado étnico tem ensejado se revelar uma estratégia eficaz de desenvolvimento sóciocultural e ambiental.

Para tanto, a atividade de turismo cultural deve considerar as reais necessidades e os anseios da comunidade, sobretudo de comunidades como Filipa, detentoras de um patrimônio cultural diferenciado. Os projetos de desenvolvimento turístico devem potencializar as especificidades naturais e culturais dos territórios, enquanto estratégia para a formatação de produtos, roteiros e atrações que valorizem as singularidades, as diferentes paisagens, os conhecimentos tradicionais e práticas culturais que constroem os lugares de identidade.

Benevides (2002, p. 25) destaca a importância dos seguintes fatores para a consolidação do turismo cultural balizado nos pressupostos da sustentabilidade:

\footnotetext{
A manutenção da identidade cultural dos lugares como próprio fator de atividade turística; uma construção de uma via democrática para o desenvolvimento de certas localidades, articuladas pelo turismo como fator estruturante de valorização de suas potencialidades ambientais e culturais, com participação da população local na construção ativa desse processo.
}

A sustentabilidade no turismo cultural, sobretudo naquele baseado nos legados étnicos, pressupõe uma atenção especialmente voltada para as especificidades locais, os problemas sociais, para a diversidade cultural. A promoção da sustentabilidade está diretamente relacionada a uma concepção estratégica e em longo prazo de 
desenvolvimento que deve se apoiar segundo Irving (2003) numa interpretação interdisciplinar e integral da dinâmica das comunidades tradicionais.

A construção da sustentabilidade no turismo é conseqüência da responsabilidade de todos os envolvidos, um processo complexo que exige adaptações, mudanças, propõe agendas e modelos para políticas públicas e, principalmente, compromisso com seus princípios. Para alguns é ainda somente uma utopia, mas para muitos tem se tornado cada vez mais uma realidade, sobretudo para aquelas pessoas, grupos sociais e principalmente comunidades onde os princípios encontram reflexos nas representações e reproduções das relações sociais e estão transformando as realidades locais. Reportando-se à cultura, segundo Rodríguez (1997, p. 58):

\footnotetext{
A dimensão cultural busca nas raízes endógenas, a diversidade e a pluralidade cultural, pela preservação do patrimônio, dos recursos culturais em respeito aos modelos autóctones. Através da capacidade de autogestão das comunidades locais, participando na tomada de decisões, procura sistemas alternativos de tecnologia e produção.
}

Praticado segundo essas diretrizes, valorizando as experiências comunitárias e a participação efetiva em todas as etapas da atividade, o turismo cultural que compartilha os princípios do etnodesenvolvimento, bem como os elementos básicos que impulsionam as comunidades quilombolas, é possível vislumbrar uma perspectiva potencial de um desenvolvimento holístico que proporcione de fato a melhoria desejada pelas comunidades tradicionais ao seu padrão de qualidade de vida.

No processo de organização da atividade turística como alternativa de renda e melhoria da qualidade de vida de seus moradores e geradora de sustentabilidade, os aspectos que marcam os laços de reconhecimento cultural e pertencimento da comunidade podem ser determinantes para o modelo de desenvolvimento que a comunidade deseja implantar e se corresponderá aos resultados e benefícios que almeja.

\section{CONSIDERAÇÕES FINAIS}

Territórios étnicos podem traduzir-se em um elo de identidade e pertença entre os grupos sociais, ao mesmo tempo para os turistas, podem transmutar-se em um cenário estratégico para o atendimento de suas necessidades de evasão, ócio e lazer. O Turismo \& Sociedade, Curitiba, v. 3, n. 2, p. 203-219, outubro de 2010 
etnodesenvolvimento alicerçado no turismo cultural possibilita às comunidades fortalecerem o sentimento de pertença e desenvolverem a sua capacidade de autogestão, no sentido de construir novas formas de produção de serviços para o turismo, sem padronização, com autenticidade e de maneira criativa, baseado no compromisso, na participação e na solidariedade.

O turismo étnico se conforma desse modo num processo de descoberta e de construção coletiva, quando as comunidades tradicionais discutem e determinam o que querem, o que podem e como querem fazer para o desenvolvimento dos seus territórios e dos agentes que nele habitam. A comunidade quilombola de Filipa tem vivenciado esse processo, por meio da arregimentação de seu patrimônio cultural, de suas memórias e tradições pela atividade turística.

No intuito de estabelecer uma relação harmônica entre turismo étnico e comunidades tradicionais torna-se necessário promover uma gestão compartilhada dos recursos e valores locais, capaz de conciliar os projetos de desenvolvimento econômico e a elevação da qualidade de vida para os segmentos sociais.

As particularidades dos territórios étnico-culturais devem ser consideradas e potencializadas no decorrer da formatação de produtos turísticos, promovendo maior articulação entre os agentes locais, visando ao alcance da sustentabilidade dos projetos turísticos.

\section{REFERÊNCIAS}

BAHL, M. Viagens e roteiros turísticos. Curitiba: Protexto, 2004.

BENEVIDES, I. P. Turismo e PRODETUR: dimensões e olhares em parceria. Fortaleza: EUFC, 2002.

BENI, M. C. Análise estrutural do turismo. São Paulo: SENAC, 2002.

BRASIL, Ministério do Turismo. Turismo Cultural: Orientações básicas. Brasília: Ministério do Turismo, 2006.

BRASIL. Decreto $\mathrm{n}^{0} 6.040$ de 07/02/2007. Institui a Política Nacional de Desenvolvimento Sustentável dos Povos e Comunidades tradicionais - PNPCT. Disponível em: <htpp: //www.planalo.gov.br/ccivil_03/Ato2007-2010/2007/Decreto/ D6040.htm>. Acesso em: 08/05/2010.

Turismo \& Sociedade, Curitiba, v. 3, n. 2, p. 203-219, outubro de 2010 
CANCLINI, N. G. Culturas híbridas: Estratégias para entrar e sair da modernidade. Trad. Heloísa Pezza Cintrão, Ana Regina Lessa. 3. ed. São Paulo: Edusp, 2000.

CASTELLS, M. O Poder da identidade. São Paulo: Paz e Terra, 1999.

COSTA, F. R. Turismo e patrimônio cultural: interpretação e qualificação. São Paulo: SENAC, 2009.

DENCKER, A. de F. M. Métodos e técnicas de pesquisa em turismo. São Paulo: Futura, 1998.

DIEGUES, A. C. S.; ARRUDA, R. S. V. Saberes tradicionais e biodiversidade no Brasil. 4. ed. Brasília: Ministério do Meio Ambiente, 2001.

FARIAS, G. A participação da comunidade no planejamento do turismo. Turismo: tendências e debates. Salvador, ano V, n. 5, p. 29-33, jan./jun. 2003.

GRABURN, N. Antropologia ou Antropologias do Turismo? In: GRUNEWALD, R. de A.; GRABURN, N.; BARRETTO, M.; STEIL, C. A.; SANTOS, R. J. dos. (Orgs.) Turismo e Antropologia: novas abordagens. São Paulo: Papirus, 2009, p. 13- 52.

GRÜNEWALD, R. de A. A Reserva da Jaqueira: Etnodesenvolvimento e Turismo. In: RIEDL, M.; ALMEIDA, J. A.; VIANA, A. L. B. (Orgs.). Turismo Rural: tendências e sustentabilidade. Santa Cruz do Sul: EDUSC, 2002.

HAESBAERT, R. Identidades Territoriais. In: ROSENDAHL, Z. (Org.). Manifestações da cultura no espaço. Rio de Janeiro: EdUerj, 1999.

HALL, S. A identidade cultural na pós-modernidade. Rio de Janeiro: DP\&A editora, 2001.

IRVING, M. de A. Turismo como instrumento de desenvolvimento local. In: D’ÁVILA, M. I.; ROSA, P. (Orgs.). Tecendo o desenvolvimento. Rio de janeiro: Mauad, 2003.

MOESCH, M. Animal Kingdom: um estudo preliminar. In: CASTROGIOVANNI, A. C. Turismo Urbano. São Paulo: Contexto, 2001, p. 89-98.

MURTA, S. M.; ALBANO, C. Interpretação, preservação e turismo. In: MURTA, S. M.; ALBANO, C. (Orgs.). Interpretar o patrimônio: um exercício do olhar. Belo Horizonte: UFMG, 2002.

ORGANIZAÇÃO MUNDIAL DO TURISMO. Turismo Internacional uma perspectiva global. 2. ed. Porto Alegre: Bookman, 2003.

POLLAK, M. Memória, Esquecimento, Silêncio. In: Revista Estudos Históricos. Rio de Janeiro, v. 2, n. 3, p. 3-15, 1989. 
POUTIGNAT, P.; STREIFF-FERNART, J. Teorias da etnicidade: seguido de grupos étnicos e suas fronteiras de Fredrik Barth. São Paulo: UNESP, 1998.

RODRIGUÉZ, J. M. M. Desenvolvimento Sustentável: níveis conceituais e modelos. In: CAVALCANTI, A. P. B. (Org.). Desenvolvimento Sustentável e planejamento: bases teóricas e conceituais. Fortaleza: UFC- Imprensa Universitária, 1997.

SANTANA, A. Antropologia do turismo: analogias, encontros e relações. Tradução de Eleonora Frenkel Barretto. São Paulo: Aleph, 2009.

SODRÉ, M. Claros e escuros: identidade, povo e mídia no Brasil. Vozes, Petrópolis, 1999.

SILVA, A. V. M. Kalunga: identidade étnica de uma comunidade remanescente de quilombo. Amsterdã: Urije Universiteite, 2004.

SILVA, R. E. da. Sustentabilidade e Turismo: Uma relação possível em Filipa - MA. Monografia (Graduação em Turismo) - Universidade Federal do Maranhão, São Luís, 2003.

URRY, J. O olhar do turista: lazer e viagens nas sociedades contemporâneas. São Paulo: EDUSC, 1996.

YÚDICE, G. A conveniência da cultura: usos da cultura na era global. Belo Horizonte: UFMG, 2004.

ZANIRATO, S. H.; RIBEIRO, W. C. Patrimônio cultural: a percepção da natureza como um bem não renovável. In: Revista Brasileira de História, v. 26, n. 51, 2006.

ZAOUAL, H. Nova economia das iniciativas locais: uma introdução ao pensamento pós-global. Rio de Janeiro: DP\&A, 2006.

Recebido em: 05/07/2010.

Aprovado em: 05/08/2010. 